\title{
A Sociological Investigation of Awareness and Causes of Intimate Partner Violence in Nigeria: A Survey of Agege, Lagos State.
}

\author{
Matthias Olufemi Dada Ojo \\ ${ }^{1}$ Department of Sociology, Crawford University of the Apostolic Faith Mission, Igbesa, Nigeria \\ Correspondence: Matthias Olufemi Dada Ojo, Department of Sociology, Crawford University of the Apostolic \\ Faith Mission, Igbesa, Ogun State, Nigeria. Tel: 234-703-795-1643. E-mail: femfemty@yahoo.com
}

Received: November 20, 2012 Accepted: December 22, 2012 Online Published: January 28, 2013

doi:10.5539/ass.v9n2p231 URL: http://dx.doi.org/10.5539/ass.v9n2p231

\begin{abstract}
This paper investigated Intimate Partner Violence in the densely populated area of Agege, Lagos State, Nigeria. The study utilized survey design in the collection of data. The study area was purposely selected and convenience sampling was used in the selection of the respondents that participated in the study [ $\mathrm{n}=120]$. Questionnaire was the instrument of data collection employed and percentage and Chi-Square were used in analyzing the quantitative data. The results of analyses show that there is much to be done in creating awareness of Intimate Partner Violence in area of its criminal and legal implication. Drunkenness, infidelity, rudeness, hatred and excessive rights of men over women were identified social factors which induce IPV. While joblessness and financial dependence of women on their partners were the economic factors noticed in the study. The study recommends creation of more awareness on Intimate Partner Violence, peaceful coexistence within the family, the assistances from the society at large and assistances and supports from the government and non-government organizations, in order to quench the problem of Intimate Partner Violence in Nigerian Society.
\end{abstract}

Keywords: IPV, awareness, violence, factors and family

\section{Introduction}

Intimate Partner Violence [IPV] is a common occurrence in many homes in Nigeria. The increase in the numbers of the occurrence globally has made it an issue which calls for drastic attention. Intimate Partner Violence is a highly prevalent and severe problem in the United States and other societies where it has been studied. It is a national problem in every country, affecting millions of adults every year [Knutson, Lawrence, Taber, Bank and Degermo, 2009; Fang and Corso 2008]. Partner violence has been socially constructed as a predominantly masculine deviance, whereby male use their power and control gained through socialization to dominate women [Bailey, Eistikovits and Buchibinder, 2012]. It is the use of actual or threatened physical, sexual and psychological violence by a current partner [Nouri et al 2012].

Intimate Partner Violence [IPV] is a sub set of family violence or domestic abuse. Family violence itself is defined as 'a spectrum of harmful acts within families that are beyond normally accepted family dynamics which encompasses sibling violence, elder abuse, child maltreatment, dating violence, and Intimate Partner Violence' [Smith and Ireland 2009: 493]. Intimate Partner Violence is a domestic form of abuse which is a forceful tactic, intentionally employed by family members to cause physical and /or psychological harm to the victim [Aysa-Lastra, Rojas ,Dillon, Duan and Rosa 2012]. This violence occurs in all countries and socioeconomic groups; however, its prevalence and manifestations vary widely [Tartakovsky and Mezhibovsky, 2012]

In Nigeria, Abama and Kwaja [2009] argued that violence against women is a prevalent harm to the basic rights, freedom health and welfare of women. It occurs in many settings and at many hands, including those of relatives, acquaintances, employers, and the state. According to the authors; most forms of violence directed specifically against women in Nigeria are met with silence not only by the state but also by much of the human rights community. The problematic issue is that Intimate Partner Violence [IPV] awareness is very low in the country. In Nigeria, Intimate Partner Violence is considered to be a relatively minor social problem. Many Nigerians are not aware that it is a major and problematic issue within the country. Most Nigerians are not aware of it as a criminal offence in the society. It is considered as a normal routine in every Nigerian's household. Many social and economical factors had been considered as factors, which caused Intimate Partner Violence within most Nigerian homes. However, there are more hidden social and economic factors needed to be identified to broaden 
our knowledge on the causes of this social problem.

This research work was bothered with the following fundamental questions which piloted the direction of this research work:

1) What is the level of awareness of the people pertaining to Intimate Partner violence?

2) What are some common socio-economic factors which instigate intimate partner violence?

As a result of these pivotal questions the objectives of the research work were.

1) To investigate the awareness of the people on Intimate Partner Violence.

2) To identify some common socio-economic factors, which cause Intimate Partner Violence.

\section{Literature Review}

The problem of Intimate Partner Violence is one which exists in all the countries of the world. It is a social problem which occurs in the developed countries as well as developing countries of the world. It has been a problem which has attracted the attention of the global community.

Letourneau, Duffy and Duffett-Leger [2012] argued that estimate of women's lifetime exposure to Intimate Partner Violence by husbands, partners, or boyfriends range between $8 \%$ and $66 \%$ dependent upon the study sample and definition of abuse. In American, 7 million Children are living in severely violent homes, defined as homes in which partners kicked, beat up, choked, or used a weapon during violent acts [Howell, Miller and Graham-Bergmann, 2012]. Surveys conducted had shown that $21-34 \%$ of women will be physically victimized by an intimate male during adulthood [Knutson et al, 2009] and that according to census-based population projections, more than a million women each year and upward of 21 million women in their lifetimes will be victimized by a current or former spouse or cohabitating partner in America [Macy, Ermentrout and Rizo, 2012].

This Domestic Violence [IPV] is not confined to any segment of society as it occurs across ethnic, racial and socio-economic boundaries and the rates are similar across rural and urban area [Valentine, Oehme and Martin 2012]. The perpetrators include people from all occupations of life, this include even officers charged with enforcing the law against perpetrators.

Intimate Partner Violence has been identified as a significant public health problem [Nouri et al, 2012]. It is a social and health problem in all societies and cultures all over the globe [Al-Badayneh, 2012]. This domestic violence has been identified as a serious epidemic public health tragedy by researchers and many governments of the world nations. [Valentine et al, 2012; Ramirez, 2011; Gracial, Herrero, Fuente and Lina, 2008]

Women are particularly vulnerable to Intimate Partner Violence during pregnancy and post partum periods. Fifty-six percent of women who report wife assault are between the ages of 18 and 34, the period that coincides with the child bearing years. Moreover, mothers of young children are more likely to suffer serious physical injuries and to fear for their lives than other abused women [Letourneau et al, 2012].

\subsection{Causes of Intimate Partner Violence}

The causes of Intimate Partner Violence are very many and very complex. Bailey et al [2012] argued that it has become increasingly clear that this phenomenon is complex and needs to be examined in the context of multiple risk factors on various ecological levels such as family, community and personality variables, along the well established gender related variables.

Some Socio-cultural factors have been identified as causes of Intimate Partner Violence. Tartakovsky and Mezhibovsky [2012] opined that certain cultural groups accept violence against women as a means of conflict resolution and as a culturally appropriate means of punishing women for their transgression of culturally sanctioned norms of behaviours. Mahapatra [2012] observed that some communities have their own socio-cultural expressions of violence against women, such as high degrees of secretiveness or emphasis on close family ties that discourage women from disclosing abuse, or self-blame due to one's actions in previous lives.

Manapatra [2012] identified social-cultural factors like: isolation, lack of social support, acculturation and patriarchy as factors associated with domestic violence like Intimate Partner Violence among the communities. Isolation from spouse/partner and perceived support predicted abuse. Culture, societal norms and history of the community may cause and encourage abuse. Patriarchal system in some societies endorsed domestic violence against women. Patriarchy can result in large differences in gender roles and power relationships and can serve to sanction male domination over women, including domestic violence in many societies [Mahapatra, 2012].

Al-Badayneh [2012] gave the illustration of Jordanian society to support cultural cause of violence in the homes. 
The author argued that in the Jordan society, social culture accepts the use of violence with children or women as a kind of discipline, and this acceptance is supported by cultural and social norms. Violence against women in Jordanian Society is widely regarded as a family matter that affects large numbers of children and adult. Jordanian women are victimized physically, psychologically and sexually by a wide range of behaviours that occur in a variety of cultural and social context. As a compliment to cultural factors is neighborhood social disorder. Gracial et al [2008] opined that deprivation and disorder in residential areas can contribute to create a climate of tolerance and acceptability of Partner Violence against women.

Violence against Intimate Partner affects the generation to come as a result of its intergenerational transaction property [Al-Badayneh, 2012]. There is a common assumption of an intergenerational transmission of violence. This is applicable to violence perpetrated by men in families against children and most especially, the adult marital or dating partners [Dankoski et al, 2006]. Early experiences of intimate violence have also been linked with violence perpetrated outside the family as a juvenile or adult [Dankoski et al, 2006].

Researchers have identified many negative consequences of childhood abuse which include: poor parenting practices, substance abuse, depression, anxiety, interpersonal problems and very importantly Partner Violence [IPV] [Swartz et al, 2012]. Whiting et al [2009] argued in their research work that children who experience physical or sexual abuse are at higher risk for a variety of emotional, behavioural, psychological and relational problems. They argue that there is a connection between experiencing abuse as a child and being in a violent relationship as an adult. Experiencing violence as a child increases the likelihood violence in one's adult intimate relationship. In a similar link, O' Donnell et al [2006] identified middle - school aggression as a significant risk factor for partner victimization and perpetration. They contested that early aggression remains an independent predictor of Partner Violence perpetration and victimization.

Forceful marriage is another factor which may cause Intimate Partner Violence and sustain it. Forceful early marriages are source of suppressing women. It brings lack of confidence to the victims and this encouraged the Intimate Partner Violence perpetrators husbands to be more authoritative [Bukhari, 2010]. The author also cited feudal system, weak law implementation and lack of awareness in male dominated society as complimentary factors which aid intimate partner violence.

Parvez and Roshan [2010] observed that media system can cause and encourage Intimate Partner Violence. The authors argued that the media projects an image of devalued, inferior and economically and emotionally dependent women in our society. They noted that overall media treatment of women can best be described as narrow and that women are rarely portrayed as rational, active or decisive in our society. This invariably gave a positive nod in favour of violence against women at homes and outside the homes. The situation of Intimate Partner Violence will be more complicated in such homes, especially if the abusers or batterers are equally abusers of alcohol [Valentine et al, 2012] or when the violent spouses are smokers, drug addicts or mentally ill [Nouri et al, 2012].

High level of education can play an important role in playing one on high social status. Education can be a protective mechanism against abuser and violence. Al-Badayneh [2012], in the study of violence against women in Jordan, argued that ANOVA analysis showed significant differences in violence against women as a result of women's education. Nouri et al [2012] discovered the same thing. They discovered a positive significant relationship between Intimate Partner Violence and educational levels of the women. The higher the educational levels of the women, the lower the possibility of the abuse. There is evidence that women, with less education, are generally more likely to experience violence than those with higher levels of education. Enrolment in and completion of secondary education is also a critical area of concern as it is clearly associated with employment opportunities and women's empowerment [Abama and Kwaja, 2009, Al-Badayneh, 2012]. Education can also act as an eye opener to the victim in making report of the act of violence to the lawful authority. The higher the education the greater the possibility of making such report [Melto, 2012]. Very similar to the factor of education is the factor of religion. Religion can play a prominent role in the factor of Intimate Partner Violence. Nouri and colleagues [2012] discovered in their study that weakness in religious persuasion is a significant predictor of Intimate Partner Violence. The stronger the religious persuasion, the lower the possibility of engaging in Intimate Partner Violence. The situation would be opposite in a community where religious beliefs sanctioned violence against partner [Mahapatra, 2012].

Poverty and poor economic condition can cause Intimate Partner Violence [IPV]. Violence against intimate partner occurs in all social and economic classes, but women living in poverty are more likely to experience violence. It is clear that poverty and its associated stressors are important circumstances [unemployment, little job autonomy, low socio economic status or blocked advancement due to lack of education] may resort to 
violence out of frustration, and a sense of hopelessness. At the same time, poor women who experience violence may have fewer resources to escape violence in the homes [Abama and kwaja, 2009]. According to Mahapatra [2012], economic control by male partners has been strongly identified as a factor contributing to Intimate Partner Violence, and in the study conducted by Smith [2008], the importance of the bread winner role in the construction of masculine identity plays a significant role. The author argued that the impediment towards the men's ability to successfully meet their proscribed masculine role and carry-out the breadwinner role has been identified as a significant 'trigger' to male battering. Hence, economic deprivation and social impoverishment can foster a culture of tolerance, where violence can be seen as an acceptable way to solve interpersonal conflicts or to increase personal status [Gracia et al, 2008].

Finally, the State and criminal Justice system may also reinforce and encourage Intimate Partner Violence. Bukhari [2010], strongly protested that the structure of the state, state law and the courts are far away from being unbiased, and because of their close linkage to culture and custom, reflect the leading ideology of the time. Historically, Intimate Partner Abuse was viewed as a private matter in which the Criminal Justice System had little interest and took no action unless the violence resulted in serious injury or death [Melton, 2012]. Letourneau et al [2012] discovered from their findings that mothers affected by domestic violence are confronted with negative attitudes and ineffectual practices within convoluted bureaucratic Criminal Justice System, leaving many feeling re-victim.

\subsection{Forms of Intimate Partner Violence}

The means of perpetrating the act of Intimate Partner Violence often focus on physical violence. While physical violence may be used to control the partner, the abuser will typically employ variety of tactics to achieve control. These can include verbal abuse, controlling money, and isolating a partner from friends, family and the outside world. Abuse may also involve exploiting partner's faith or subculture. These tactics serve to gain compliance and entrap victims in relationship by disempowering them and making it difficult for them to reach out for help or to leave [Cares and Cusick, 2012].

\subsection{Effects of Intimate Partner Violence}

The effects of Intimate Partner Violence are very enormous on the female partners and their children in the family. These effects have translated the issue of Intimate partner violence into a high public health problem [Ramirez, 2011].

For the mothers, a growing body of research has shown that Intimate Partner Violence affects mothers' parenting behaviours and parent - child relationship. It is associated with less effective parenting of young children. A large body of research has revealed that Intimate Partner Violence causes negative impacts of depression on parenting. Depression may play a role in explaining how mothers' Intimate Partner experiences affect parenting behaviours and parent - child relationships [Murray et al, 2012].

Tailor and Letourneau [2012] discovered that Intimate Partner Violence has impacts on the infants in the families where it is carried out. Infants [birth to 3 years] in particular, tend to be more negatively affected by violence exposure than older children, resulting in greater emotional problems, social problems, developmental delays, aggression, trauma systems, and less verbal motor and cognitive abilities than standardized norms.

Intimate Partner Violence [IPV] can cause damage to the health statuses of the children Kuhlman et al [2012] and Whiting et al [2009] argued that exposure to violence and traumatic events during childhood has long been associated with poor physical and psychological health during adulthood. They found that children exhibiting more traumatic stress symptoms displayed total health problems. Gastrointestinal problems and asthma were related to poor psychological adjustment and that pre-school - age girls were related to poor psychological adjustment and that pre-school-age girls were more likely to display health problems than boys.

Intimate Partner Violence also exhibits negative effects on the children. Knutson et al [2012] discovered that child exposure to Intimate Partner Violence is a threat to the psycho-social and academic well-being of children. In a related issue, Howell et al [2012] argued that, it impedes the measures of positive functioning for pre-school children. Children experiencing Intimate Partner Violence at homes can be affected behaviouraly during their adolescent stage. Herrenkohl,T.I and Herrenkohl,R.C [2007] claimed a strong association between child witnessing domestic violence and stressors like family conflict, personal problems of parents and external constraint on the family as predictive of internalizing and externalizing behaviours in adolescents. In the same way, Moylan et al [2010] confirmed in their study, that domestic violence and child abuse increase child's risk for internalizing and externalizing outcomes in adolescence and that previous studies have demonstrated that children exposed to domestic violence i.e IPV are more likely to experience a wide range of adverse 
psychosocial and behavioural outcomes. Youth's exposure to violence is linked not only to adjustment problems during childhood but also to later problems during adolescence and adulthood [Margolin et al, 2009]. In the same direction, Ireland and Smith [2009] proved that children raised in Intimate Partner Violence homes are at risk for a range of problem outcomes including antisocial behaviour in adolescence and adulthood and that such has become a predictor of crime and antisocial behavior during adolescence. Hence, the experience of family violence is a risk factor for children's delinquency specifically, and antisocial behaviour more generally [Smith and Ireland, 2009]. It has been identified as a risk factor for aggression, delinquency and involvement with Criminal Justice System.

Studies have uncovered the significant relationship between Intimate Partner Violence and suicide among the partners' children who witnessed the violence. Hooven et al [2012] argued that childhood experience of violence and victimization are implicated in significant psyche- social difficulties in young adulthood, including depression, anxiety, aggression and suicide. Miller and associates [2012] argued that present study has examined the association of family conflict and family cohesion with adolescent Suicide. Result indicated that family cohesion was significantly and inversely associated with suicide. Their findings suggest that it may be important to assess suicide among adolescents reporting high family conflict and low family cohesion. They argued that lack of trust in people and interpersonal relationships results in problematic attachments with the outside world as well as increased feelings of loneliness and isolation. Ultimately, poor interpersonal family environments that are as a result of ineffective and non satisfying relationships contribute to the development of depression, a common precursor to suicide.

Intimate Partner Violence has been identified as a social catalyst for child abuse which is another prevailing social problem world- wide. Moylan et al [2010] suggested that many children who witness domestic violence have also directly experienced child abuse. Whiting et al [2009] also observed the same link. They argued that Intimate Partner Violence [IVP] between adults is significantly related to the abuse of children in the home and that many forms of childhood abuse are associated with an increased likelihood of adult violence.

There is intergenerational transmission of violence [Dankosk et al, 2006]. Children who had witnessed Intimate Partner Violence of their parents turned out to be perpetrators of the act and the females may accept it as a normal life challenge that must be coped with. Whiting and colleagues [2009] had demonstrated connections between experiencing abuse as a child and being in a violent relationship as an adult. In the same way, Fang and Corso [2008] argued that several studies have found that children who experienced violence are more likely, as adults, to engage in Intimate Partner Violence. Smith [2008], in his study of African American men and Intimate Partner Violence discovered that many boys who grew up in violent homes because of the impact of the abuse they witnessed or experienced, ended up being offenders of Intimate Partner Violence. Hence, the act is carried from one generation to the other.

\subsection{Solutions to Intimate Partner Violence}

Intimate Partner Violence is a social problem that can be solved or at least reduced drastically. Aysa-Lastral et al [2012] offered a solution from family level. They argued that family members' closeness can be a protective factor against this abuse. They observed that long-lasting relations within the family can end the problem. O' Donell et al [2006] suggested that partner violence can be solved through young adulthood intervention. Their findings suggested the importance of early interventions that help adolescents learn non-violent strategies for resolving conflicts in cross-gender relationships. This can be done by incorporating violence prevention into a range of existing programmes and services for youth and adults.

Abama and kwaja [2009] provided many means through which partner violence can be eradicated. These include visible and sustained leadership by politicians and other key figures in the society, communication campaigns aimed at changing norms and attitudes, law reform on issues such as property rights, divorce, and political participation, and credit and skill building programmes to increase women's economic independence and empowerment.

Furthermore, interventions which include: enactment and enforcement of sanction against men who perpetrate violence against partners; training of judiciary, police and health care workers to recognize and deal appropriately with violence against women, and services for women experiencing violence, such as shelters, telephone hotlines; psychological and legal advice and support networks must be embarked upon [Abama and Kwaja, 2009]

Additionally, some strategies can be put in place to forestall the problem. These include: women access to certain jobs, education or governance positions, provision of gender-sensitive budgets that support equitable allocation of resources and provision of health and social services that would respond to women who suffered Intimate 
Partner Violence in our society [Abama and Kwaja, 2009].

\section{Methodology Applied}

This study was conducted through the selection of samples from the entire population of the study area. Survey design was implemented. Survey research involves the collection of information from a sample of individuals through their responses to questions [Schutt, 2004].

Agege in Lagos State, Nigeria, was our study area. Agege is under Ikeja division of the state. The total population of the area was put at 459,939 with 238,456 male and 23,287 female respectively. This was the official figures of the National Census conducted in 2006. However, the parallel census conducted by Lagos State put the total figure to be 1,033,064 with 564,239 male and 468,826 female respectively [Idowu et al, 2011]. The total figures released by Lagos State is, however, more realistic and was relied on for the purpose of this study. The study covered notable areas in Agege, Lagos State like Dopemu, Shasa, Akowonjo, Ipaja, Gbotikuyo, Oko-Oba and Orile-Agege. Our study population consists of adult males and females of Agege area. The study area was chosen because it is a densely populated area of the state which is very close to the state capital. However, it is not possible to study every unit of the population. Hence, samples were taken from the entire population. At the end of the sampling procedure 120 people were selected, who participated in the survey.

The sampling method involved multi-stage sampling techniques. Because the area is densely populated, and therefore serves the purpose of the research, the study area [Agege] which was the site of the research was purposely sampled. The unit [study area] was selected based on our judgment that it will facilitate our investigation [Adler and Clark, 1999]. For the sampling of our respondents, who participated in the study, convenience sampling was implemented. The sampling method was implemented because it was very cheap and quick [Neuman, 2003]. It was relatively inexpensive, considering the time and money [Adler and Clark 1999]. As stated earlier on, our sample size was 120 people, selected from the study area.

Questionnaire was the instrument of data collection we employed. The questionnaires were delivered by hand and were later collected back from the participants. Enough time was given to the respondent to fill the questionnaires [2 weeks] before we collected them. It was individually administered questionnaire, although more expensive in cost and time but it yielded a better response rate [Adler and Clark, 1999].

Intimate Partner Violence is a common social problem, virtually in many homes in Nigeria. However, our study was restricted to Lagos State [being a very densely populated state in Nigeria]. Agege was selected from Lagos State. It was not possible to study all the parts of Lagos State. We considered the time and the monetary cost. This was a self sponsored research study. This study was purely quantitative study. The data and information were derived from the questionnaires given out to the respondents. The quantitative data supplied were subjected to frequency and percentage analyses. The hypotheses were tested using chi-square.

The following were the hypotheses tested:

1) There is a significant relationship between Intimate Partner Violence and bad economic condition.

2) There is a significant relationship between social factors and Intimate Partner Violence.

We took the issue of research ethics into strong consideration before we embarked on our study. Consents of the participants were sought, having explained the purposes of the research to them. The anonymity of the respondents was taken into account. The information supplied were analyzed and interpreted in aggregates without any link to any respondents. The data and information were kept confidential and were used only for this research work.

\section{Data Presentation, Data Analyses and Data Interpretation}

Table 1. Table showing the socio-bio data of the respondents

\begin{tabular}{ccc}
\hline Data variable & Frequency & Percentage \\
\hline Sex & & 58 \\
Male & 70 & 42 \\
female & 50 & $\mathbf{1 0 0}$
\end{tabular}


Age

15-24

25-40

41 above

Total

MARITAL STATUS

Single

Married

Divorced

Widow

Total

\section{ETHNIC GROUP}

Yoruba

Igbo

Hausa

Other Ethnic Minorities

Total

$\begin{array}{cc}50 & 42 \\ 64 & 53 \\ 6 & 5 \\ \mathbf{1 2 0} & \mathbf{1 0 0}\end{array}$

14

12

$100 \quad 82$

$4 \quad 3.3$

2

$120 \quad 100$

$78 \quad 65$

$22 \quad 18$

$14 \quad 12$

625

$120 \quad 100$

Source: Field Survey, 2012

Intimate Partner Violence is a social phenomenon between male and female. 70 of our respondents [58\%] were men, while 50 of them [42\%] were women. Being an issue centred on both sexes, the involvement of the two sexes availed us the opportunity to gather responses and views on the matter of Intimate Partner Violence without being one sided.

We considered the age of our respondents. 50 respondents [42\%] were between the age range of 15-24 years. 64 respondents [53\%] were between 25 and 40 years, and 6 respondents [5\%] were 41 years and above. A cursory look at the age distributions of our respondents shows that most of them were young and fell within marital age range.

Marital status was a crucial variable considered in our study. The study has to do with marital issue. Hence, marital status of our respondents were taken into cognizance. Only 14 out of our respondents were single [12\%]. 100 out of our respondents were married [83\%]. 4 respondents [3.3\%] were divorcees and 2 respondents [1.7\%] were widower/widow. The over whelming number of our respondents that were married shows that majority of our respondents were within the purview of our study. The study centred on the issue of marriage/ cohabitation which is an Intimate Relationship. With this, it was presumed that majority of our respondents were familiar with the matter of Intimate Partner Violence.

Ethnic groups of our respondents were also taken into consideration. 78 out of our respondents [65\%] were Yoruba, 22 respondents [18\%] were Igbo, 14 respondents [12\%] were Hausa and finally, 6 respondents [5\%] were from other ethnic groups in the country like Efik, IJaw, Urhobo etc. Lagos State is a predominantly a Yoruba state, Hence, it was not unexpected that the Yoruba among our respondents were in the majority.

Table 2. Table showing the awareness variables of IPV and responses

\begin{tabular}{llrll}
\hline Awareness Variables & YES & & No & \\
& Frequency & $\%$ & Frequency & $\%$ \\
\hline Heard of IPV? & 106 & 88 & 14 & 12 \\
Total & Frequency $=120$ & & Percentage $=100$ & \\
Witnessing someone beating his partner? & 82 & 68 & 38 & 32 \\
Total & Frequency $=120$ & & Percentage $=100$ & \\
IPV is a global reality & 74 & 62 & 46 & 38 \\
Total & Frequency $=120$ & & Percentage $=100$ &
\end{tabular}


IPV is common only among illiterates

Total

Battered partner should take a legal action against her batterer?

Total
22

Frequency $=120$

94

Frequency $=100$
$18 \quad 98$

Percentage $=100$

$78 \quad 26$

Percentage $=100$

Source: Field survey, 2012

We included some questions in our questionnaire to determine the awareness of our respondents on Intimate Partner Violence. We asked our respondents if they have heard of Intimate Partner Violence before. 106 respondents [88\%] have heard of Intimate Partner Violence in the past ,although they knew it in different words like wife abuse, wife beating, spouse abuse etc. However, 14 respondents [12\%] have not heard about it in the past as a social problem. Majority of our respondents who testified to the knowledge of IPV shows that people were aware of it as a social problem.

We asked our respondents to say whether they had witnessed someone beating his partner in the past. For their responses, 82 respondents [68\%] had witnessed such incidences in the past, while 38 respondents [32\%] had not witnessed such in the past. The overwhelming percentage, who had witnessed men beating their partners, further buttressed the awareness of our respondents on IPV. What one has witnessed was a clear indication of awareness or occurrence of such.

We wanted to know if our respondents were aware that Intimate Partner Violence is a criminal offence under the statutory law. 70 respondents [58\%] were quite aware of it as a criminal offence, 50 respondents [42\%] were not aware that it is a serious offence under the law. Going by the analyses, we discovered that the awareness of Intimate Partner Violence as a criminal offence was not all that strong. The percentage of unawareness was a bit high, considering the expected level of its awareness as a criminal act in the country.

We tested the awareness of our respondents on Intimate Partner Violence as a global reality which is peculiar to all nations of the world.74 respondents [62\%] admitted that the problem of IPV is worldwide. They perceived the problem to be common both to the developed countries and developing countries of the world. However, 46 respondents [38\%] considered the social problem as a localized one. These respondents perceived that it was the national and cultural factors which engineered the problem in Nigeria, something that were not found in some other countries of the world.

However, the available literature works and the researches that have been conducted demonstrated that Intimate Partner Violence is a global social problem which is plaguing all the countries of the world irrespective of development, literacy, race, ethnic group, socio-economic statuses e.t.c . For instance, literacy factor was considered as a factor which determines whether Intimate Partner Violence would be committed or not. We asked our respondents whether IPV is only perpetrated by illiterates. 22 respondents [18\%] said it is common only among uneducated men. However, 98 respondents [82\%] were of the opinion that it is common both among educated and uneducated men. This confirmed the previous findings that IPV was not limited to illiterate people alone. It is a social problem perpetrated by educated personalities all nations of the world.

Finally we asked our respondents to say whether a victim of IPV should take a legal redress. This question was asked to determine whether our respondents were aware of legal support and redress for the victims or not. 94 respondents [78\%] were aware of such legal redress and were of the opinion that the victims should take legal steps for justice. However, 26 respondents [22\%] did not favour legal action but were of the opinion that the matter can be solved amicably at the family level with intervention of family elders or religious leaders.

Table 3. Factors that cause IPV and the agreement of the respondents on them

\begin{tabular}{llllll}
\hline \multicolumn{1}{c}{ Factors } & $\begin{array}{c}\text { Respondents } \\
\text { Agreed }\end{array}$ & $\begin{array}{c}\text { Respondents } \\
\text { Disagreed }\end{array}$ & \% & Total \\
\hline High intake of alcohol by husbands can cause IPV & 106 & 88 & 14 & 12 & 120 \\
Wife rudeness can cause IPV & 96 & 80 & 24 & 20 & 120 \\
Wife Infidelity can cause IPV & 86 & 72 & 34 & 28 & 120 \\
Hatred can cause IPV & 34 & 28 & 86 & 72 & 120 \\
Excessive rights of men over women can cause IPV & 64 & 53 & 56 & 47 & 120
\end{tabular}


Husband's Joblessness can cause IPV

Wife Joblessness can cause IPV

Bad Economic Situations in the country can cause IPV

Women dependence on financial support from their partners 88 can cause IPV

$\begin{array}{lllll}92 & 77 & 28 & 23 & 120 \\ 34 & 28 & 86 & 72 & 120 \\ 64 & 53 & 56 & 47 & 120 \\ 88 & 73 & 32 & 27 & 120\end{array}$

Source: Field Survey, 2012

In an attempt to uncover likely factors that can cause Intimate Partner Violence, we introduced both the likely social factors and economic factors at the same time. The first social factor we considered was alcoholic intake by the husbands. 106 respondents [88\%] agreed that men that take excessive alcoholic drinks may commit Intimate Partner Violence. This finding compliments the finding of Valentine and his colleagues [2012] that batterers are more likely to be abusers of alcohol too. However, 14 respondents [12\%] disagreed with the belief that alcohol can cause Intimate Partner Violence. Going by the analyses, the majority that agreed that alcohol can induce IPV clearly shows that excessive alcoholic intakes by men can make them to be violent against their partners.

Wife rudeness to the husband or the extended family members of the husband is another social factor we imputed into our study. 96 respondents [80\%] firmly agreed that partners that were rude to their husbands/boyfriends or their extended family members can incur the wrath and violence from these men. 24 respondents [20\%] disagreed that rudeness of women can cause IPV. However, the experiences show that women rudeness, excessive complaints and stubbornness can warrant their partner being violent against them. Some men find it very difficult to put up with women that were rude and stubborn. Hence, rudeness and stubbornness can induce act of violence against one's partner.

Infidelity or marital unfaithfulness of the partner is another social factor we introduced. 86 respondents [72\%] firmly agreed that women that were engaged in acts of infidelity their relationships with their partners were usually the victims of Intimate Partner Violence. 24 respondents [28\%], however, disagreed that infidelity can cause Intimate Partner Violence. In African societies, infidelity is a serious offence, especially when married women committed such act. It is a sacrilegious act which can only be normalized through sacrifices. Women that are guilty of it may constantly be abused by their partners on the ground of their unfaithfulness to their partners.

Love solidifies relationships. However, where love is replaced by hatred, violence is not farfetched. 34 respondents [28\%] agreed that hatred can induce Intimate Partner Violence. However, 86 respondents [72\%] disagreed that hatred can cause Intimate Partner Violence. Although, majority of our respondents concluded that hatred is not a cause of IPV, in some situations it can be a remote cause. How can one explain living amicably with someone you do not love, under the same roof or perhaps in the same bed?

Every culture places some rights in the hand of men over women folk. Such rights may activate violence against women. 64 respondents [53\%] agreed with this fact when we sorted out and presented our data. 56 respondents [47\%], however, did not agree. Notwithstanding, going through the cultural supremacy or religious belief, men are considered to be heads of women and as a result, some rights were given to them culturally and religiously over women. It was not these rights per se that contributed to the Intimate Partner Violence but the abuse of such rights by men. When such rights are abused IPV is quite imminent.

Some economic variables were introduced to determine their impacts on the inducement of Intimate Partner Violence. Joblessness of the husbands was taken into consideration. 92 respondents [77\%] agreed that when men are unemployed or jobless, their partners at home stand the risk of being victims of IPV. A penniless partner is a violent partner. This is the belief of these respondents. Only 28 respondents [23\%] disagreed with this belief. But the previous studies have shown a correlation between joblessness and Intimate Partner Violence [Smith, 2008]. Hence, Joblessness can create a hostile environment which can variably lead to IPV.

The joblessness of the women was also taken into consideration. 34 respondents [28\%] agreed that jobless women can be victims of Intimate Partner Violence. However, 86 respondents [72\%] disagreed that it is a factor that is to reckon with. But from experience, it is known that women working to support the family finance may be respected and treated well by their husbands because of their contributory efforts in upholding the financial stands of the families. However, jobless women may be seen as a heavy burden for their men, and in the process men may retaliate with violence. In the same way, women who depend too much on their men for financial support may likely be victims of Intimate Partner Violence. 88 respondents [73\%] agreed with this, while 32 respondents [27\%] disagreed. However, study reveals that economic control by male partners can cause IPV 
[Mahapatra, 2012], while women that are financially independent may not likely be victims because they have greater propensity to leave the marital relationship [Al-Badayneh, 2012]

In overall analyses, 64 respondents [53\%] agreed that bad economic situation in the country invariably contributed to Intimate Partner Violence in Nigeria, while 56 respondents [47\%] did not agree. Although, a correlation between bad economic situation and IPV has been discovered, further studies are needed in this direction to ascertain and firmly confirm this within with Nigerian context.

\subsection{Hypotheses Testing}

We postulate two hypotheses in this study. They [hypotheses] were relationships between two or more variables [Schutt, 2004].

Our first hypothesis is stated below:

H0: There is no significant relationship between IPV and bad economic condition.

H1: There is a significant relationship between IPV and bad economic condition.

Our Decision Rule: if $\mathrm{x}^{2} \mathrm{cal}>\mathrm{x}^{2}$ tab, reject the null hypothesis [H0] and accept alternative hypothesis [H1].

Table 4. Bad economic condition causes IPV

\begin{tabular}{llll}
\hline Responses & Observed No & Expected No & O-E \\
\hline Yes & 64 & 60.0 & 4.0 \\
No & 56 & 60.0 & -4.0 \\
Total & $\mathbf{1 2 0}$ & & \\
\hline
\end{tabular}

Filed Survey, 2012

Table 5. Test statistics

\begin{tabular}{|c|c|c|c|}
\hline & & \multicolumn{2}{|c|}{ Bad economic condition causes IPV } \\
\hline Chi-square & & \multicolumn{2}{|l|}{0.533} \\
\hline df & & \multicolumn{2}{|l|}{1} \\
\hline A symp.sig & & \multicolumn{2}{|l|}{.465} \\
\hline \multicolumn{4}{|c|}{ a. $\mathrm{O}$ cells $[0 \%]$ have expected frequencies less than 5 . The minimum expected cell frequency is 60.0} \\
\hline \multicolumn{4}{|c|}{ Calculated value $=0.533$} \\
\hline \multicolumn{4}{|c|}{ Tabulated value $=3.84$} \\
\hline \multicolumn{4}{|l|}{ Degree of freedom $=1$} \\
\hline \multicolumn{4}{|c|}{ Level of significant $=0.05$} \\
\hline \multicolumn{4}{|c|}{$\begin{array}{l}\text { According to the chi-square calculated [0.533], which is less than chi-squre tabulated }[3.84] \text { at } 5 \% \text { level of } \\
\text { significance, we therefore accept the null hypothesis and reject alternative hypothesis. Hence, economic } \\
\text { condition does not have a significant relationship with IPV. }\end{array}$} \\
\hline \multicolumn{4}{|c|}{ Our second hypothesis is stated below: } \\
\hline \multicolumn{4}{|c|}{ H0: There is no significant relationship between social factors and intimate partner violence. } \\
\hline \multicolumn{4}{|c|}{ Decision rule: if $x^{2}$ cal $>x^{2}$ tab, reject the null hypothesis and accept alternative hypothesis. } \\
\hline \multicolumn{4}{|c|}{ The social factors are measured by intake of alcohol, rudeness and infidelity. } \\
\hline \multicolumn{4}{|c|}{ Table 6. Can the social factors mentioned above cause IPV? } \\
\hline Responses & Observed No & Expected No & O-E \\
\hline Yes & 106 & & \\
\hline No & 14 & 00.0 & 40.0 \\
\hline Total & 120 & 00.0 & -40.0 \\
\hline
\end{tabular}

Field Survey, 2012 
Table 7. Test statistics

\begin{tabular}{cc}
\hline & Can the mentioned social factors cause IPV \\
\hline Chi-square & 70.5339 \\
$\mathrm{df}$ & 1 \\
Asymp.sig & .000 \\
\hline
\end{tabular}

a. $\mathrm{O}$ cells $[0 \%]$ have expected frequency less than 5 . The minimum expected cell frequency is 60.0

Calculated value $=70.533$

Tabulated value $=3.81$

Degree of freedom $=1$

Level of significant $=0.05$

According to the chi-square analysis above, the calculated chi-square [70.533] is greater than the tabulated chi-square [3.84] at 5\% level of significant; we therefore rejected the null hypothesis and accepted the alternative hypothesis. Therefore, there is a significant relationship between social factor like, alcoholic partner, rudeness and infidelity and the Intimate Partner Violence.

For the commentary on our hypotheses, although the first hypothesis clearly shows that there was no significant relationship between bad economic condition and the Intimate Partner Violence however, we suggest that bad economic condition may act as intervening variable between other variables and the IPV variable. It may link such variables with IPV or help to explain the relationship between them [Schutt, 2004].

However, the second hypothesis confirmed the social factors as having significant relationship with IPV. Such factors examined in this work were drunkenness, and psycho-social factors like rudeness and infidelity.

\section{Summary of the Findings}

Although, many of our respondents were quite aware of IPV as a social problem i.e $88 \%$ has heard about it in the past, and $68 \%$ has witnessed the scenes of IPV, the $42 \%$ that was not aware of it to be criminal act clearly shows that many efforts still needed in publicity of it as criminal act. Although, $78 \%$ called that the victims should take legal action for redress, however, the follow up questions revealed that majority of them were talking of making police report, not that of taking the matter to law courts. Many were not quite aware that offenders can be prosecuted for committing violence against their partners under different legal framework .For instance rights of women and other citizens were protected in criminal code and penal code in the country and the like of it in the Muslim personal laws in Nigeria. Furthermore, the section on Fundamental Human Rights says that "a citizen of Nigeria of a particular community, ethnic group, place of origin, circumstances of birth, sex, religion or political opinion shall not be, by reason only that he or she is such, a person be discriminated against " [Okunola, and Ojo, 2012]. Additionally, rights of women were declared in the United Nations Universal Declaration on Human Rights [UDHR], the African Charter on Peoples and Human Rights, and The Convention on Elimination of All Forms of Discrimination Against Women [CEDAW], to which Nigeria is a Signatory. Hence, legal actions can be taken in law courts to protect and seek redress for Intimate Partner Violence [Okunola and Ojo, 2012].

We have identified some social factors which can induce IPV in this study. These are drunkenness, joblessness, hatred, rudeness of wife to either her husband or husband relatives and infidelity. We believe that many social factors abound that can lead to IPV. Further studies are recommended to unveil these hidden social factors.

\section{Conclusion}

Intimate Partner Violence is a worldwide phenomenon. Although, different societies continue to ignore or condone it, its effects are corrosive to the society. It is rather unfortunate that in Africa, many female scholars have not found the subject of violence against partner or violence against women as an interesting area of research. Only very few scholars have made it as a field of research interest, compared with the western world, where many researchers have been conducted on the problem and the areas associated with it, by women.

We hope that this work and the few others will provoke more debates and more research activities on the subject. If there is any practice that infringes so much on the Fundamental Human rights of women, it is Intimate Partner Violence. It is high time the subject was accorded a prime place in the midst of African scholars.

\section{Recommendation}

We present our recommendations from three principal areas: the home, society and the government/ non- 
governmental organizations.

Home is considered as haven of security, happiness, a place of socialization, and informal education. The parents are challenged to provide a favourable place of knowledge and good legacy for their children so that they will be well disciplined and cultured in any social relationships they may find themselves, especially marital relationships. From previous researches discussed in this study, child abuse has been identified as one of the factors which can contribute to Intimate Partner Violence. A child that has been abused, may, in the future, abuse his children and wife. A child witnessing violence against his mother may think it is a normal and acceptable act, and may, in the future, abuse his own partner. Hence, the couples should saddle themselves with the responsibility of understanding, respect, submissiveness, love and give due honour to their relationships. Partners should be encouraged to find peaceful ways of settling disputes or misunderstanding, instead of resulting into violence. Finally, they must learn how to submit and commit their relationship into God's hand with the fear of God which is the genesis of wisdom.

The society must be sensitized on the problem of Intimate Partner Violence. Printed materials i.e hand bill, flyers, posters, books, journals and magazines must be distributed from time to time and the contents explained to the people. Marriage counseling departments must be established at strategic locations in every local government area, to handle marriage crises which are beyond the capacity of the couples and the elderly people in the communities. Workers under these counseling departments should be encouraged to run a sectional check on the affected families to study the progress of things. Women must be encouraged to form pressure groups that will fight against Intimate Partner Violence so that they can educate other women and learn from one another. We recommend that such groups with the assistance of non-governmental organizations embark on seminars, workshops, public talks, conferences advertisement e.t.c, that will address the issue of Intimate Partner Violence. Finally, women must be empowered in our society. This will give them the opportunity to be more assertive and be well positioned to fight their rights. Hence, they must be empowered economically, politically and socially.

At the level of government and non-governmental organization, we recommend that every state should enact laws that will protect the victims of Intimate Partner Violence and at the same time, punish the offenders. We believe that if such laws are enacted and well implemented to the letter, it will curb the occurrences of the Intimate Partner Violence in the country. The Federal Government is called upon to specifically make laws that will address the problem in its totality, instead of prosecuting the offenders under the related laws. There is a clamor for government intervention on this.

We propose that government [Federal and the States] should include in our school curricula, studies that will address the issues on interpersonal relationships in the society. If our children are taught on how to relate and interact with other people, especially the opposite sex in our society, we believe it will go a long way in solving the problem of Intimate Partner Violence in our society. Such teachings must be started from primary school level to the tertiary institution in our society.

The government and non-governmental organizations are called upon to intensify campaigns against IPV in public places [rural and urban] ,organize symposia, seminars and workshops to enlighten people on danger inherent in IPV. Government and non-governmental organizations must be ready to sponsor all these programmes. Government, must wake up to empower women in the society -their 'voices' must be heard. The empowerment must be done economically, politically and socially.

Finally, we recommend further researches in areas of Intimate Partner Violence and other family/domestic violence. We commend the social researchers in the western world for their various contributions in this regard. We believe that the African social researchers and Nigerian social researchers in particular, can do the same, if not better. We therefore, recommend that Nigerian scholars should shift their research interests to the study of violence in the family. We believe that irrespective of any discipline, be it Medicine, Education, Social Sciences e.tc, there is always a place for the family/ domestic violence to be studied. Doing this will solve the problem of Violence among the domestic Intimate Partners in Nigeria and the other countries of the world.

\section{References}

Abama, E., \& Kwaja, C. M. A. (2009). Violence against Women in Nigeria: How the Millennium Development Goals Addresses the Challenge. The Journal of Pan African Studies, 3(3), 23-34.

Adler, E. S., \& Clark, R. (1999). How it is Done: An Invitation to Social Research. Canada: Wadworth Publishing Company.

Al-Badayneh, Dia, M. (2012). Violence against Women in Jordan. Journal of Family Violence, 27, 369-379. 
http://dx.doi.org/10.1007/s10896-012-9429-1

Aysa-Lastra, M., Rojas, P., Dillon, F. R., Duan, R., \& Rosa Mario De La. (2012). Family Closeness and Domestic Abuse among Caribbean and South American Women in South Florida. Journal of Family Violence, 27, 547-559. http://dx.doi.org/10.1007/s10896-012-9445-1

Bailey, B., Eistikovits, Z., \& Buchbinder, E. (2012). Battering Men and Their Male Therapists: The Different and the Similar. Journal of Family Violence, 27, 465-476. http://dx.doi.org/10.1007/s10896-012-9433-5

Bukhari, A. A. (2010). Violence against Women in Southern Punjab: Altering Trends. Pakistan Journal of Social Sciences, 30(1), 125-131.

Cares, A. C., \& Cusick, G. (2012). Risks and Opportunities of Faith and Culture: The Case of Abused Jewish Women. Journal of Family Violence, 27. http://dx.doi.org/10.1007/s10896-012-9435-3

Dankoski, M. E., Keiley, M. K., Thomas, V., Choice, P., Lioyd, S., \& Seery, B. L. (2006). Affect Regulation and the Cycle of Violence Against women: New Directions for Understanding the Process. Journal of family Violence, 21, 327-339. http://dx.doi.org/10.1007/s10896-006-9028-0

Fang, X. M., \& Corso, P. S. (2008). Gender Differences in the Connections between Violence Experience as a Child and Perpetration of Intimate Partner Violence in young Adulthood. Journal of Family Violence, 23, 303-313. http://dx.doi.org/10.1007/s10896-008-9152-0

Gracia, E., Herrero, J., Fuente, A., \& Lila, M. (2008). Neighborhood Social Disorder and Attitudes toward Partner Violence against Women: Evidence from Latin -American Immigrants in Spain. The Open Sociology Journal, 1, 1-8. http://dx.doi.org/10.2174/1874946100801010001

Herrenkohl, T. I., \& Herrenkohl Roy, C. (2007). Examining the Overlap and Prediction of Multiple Forms of Child Maltreatment, Stressors, and Socio economics Status: A Longitudinal Analysis of Youth Outcomes. Journal of family Violence, 22, 553-562. http://dx.doi.org/10.1007/s10896-007-9107-x

Hooven, C., Nurius Paula, S., Logan-Greene, P., \& Thompson Elaine, A. (2012). Childhood Violence Exposure: Cumulative and Specific Effects on Adult Mental Health. Journal of Family Violence, 27, 511-522. http://dx.doi.org/10.1007/s10896-012-9438-0

Howell, K. H., Miller, L. E., \& Graham-Bergmann, S. A. (2012). Inconsistencies in Mothers' and Group Therapists Evaluation of Resilience in Preschool Children Who Live in Households with Intimate Partner Violence. Journal of family Violence, 27, 489-497. http://dx.doi.org/10.1007/s10896-012-9446-0

Ireland, T. O., \& Smith, C. A. (2009). Living in Partner-Violent Families: Developmental Links to Antisocial Behaviour and Relationship Violence. Journal of Youth and Adolescence, 38, 323-339. http://dx.doi.org/10.1007/s10964-008-9347-y

Knutson, J. F., Lawrence, E., Taber Sarah, M., Bank, L., \& DeGarmo David, S. (2009). Assessing Children's Exposure to Intimate Partner Violence. Clinical Child Family Psychology Review, 12, 157-173. http://dx.doi.org/10.1007/s10567-009-0048-1

Kuhlman, K. R., Howell, K. H., \& Graham-Bergmann, S. A. (2012). Physical Health in Preschool Children Exposed to Intimate Partner Violence. Journal of Family Violence, 27, 499-510. http://dx.doi.org/10.1007/s10896-012-9444-2

Letourneau, N., Duffy, L., \& Duffett-Leger, L. (2012). Mothers Affected by Domestic Violence: Intersections and Opportunities with the Justice System. Journal of Family Violence, 27. http://dx.doi.org/10.1007/s10896-012-9451-3

Macy et al. (2012). An Innovative Program for Justice-Involved Partner Violence Victims: "No Man is worth Me Getting Locked Up". Journal of Family Violence, 27, 453-464. http://dx.doi.org/10.1007/s10896-012-9436-2

Mahapatra, N. (2012). South Asian Women in the US and their Experience of Domestic Violence. Journal of Family Violence, 27, 381-390. http://dx.doi.org/10.1007/s10896-012-9434-4

Margolin et al. (2009). Youth Exposed to Violence: Stability, Co-occurrence, and Context. Clinical Child Family Psychology Review, 12, 39-54. http://dx.doi.org/10.1007/s10567-009-0040-9

Melton, H. C. (2012). Stalking, Intimate Partner Abuse, and the Police. The Open Criminology Journal, 5, 1-7. http://dx.doi.org/10.2174/1874917801205010001

Miller, E., McCullough, C., \& Johnson, J. G. (2012). The Association of Family Risk Factors with Suicidality among Adolescent Primary Care Patients. Journal of Family Violence, 27, 523-529. http://dx.doi.org/10.1007/s10896-012-9443-3

Moyian et al. (2010). The Effects of Child Abuse Exposure to Domestic Violence on Adolescent Internalizing and Externalizing Behaviour Problems. Journal of Family Violence, 25, 53-63. http://dx.doi.org/10.1007/s10896-009-9269-9

Murray et al. (2012). The Impact of Intimate Partner Violence on Mothers' Parenting Practices for Urban, 
Low-Income Adolescents. Journal of Family Violence, 27. http://dx.doi.org/10.1007/s10896-012-9449-x

Neuman, W. L. (2003). Social Research Methods: Qualitative and Quantitative Approaches (5th ed.). USA: A and $\mathrm{B}$.

Nouri et al. (2012). Prevalence and Determinants of Intimate Partner Violence against Women in Marivan County. Iran Journal of Family Violence, 27, 391-399. http://dx.doi.org/10.1007/s10896-012-9440-6

O' Donnell et al. (2006). Middle School Aggression and Subsequent Intimate Partner Physical Violence. Journal of Youth and Adolescence, 35, 693-703. http://dx.doi.org/10.1007/s10964-006-9086-x

Okunola, R. A., \& Ojo, M. O. D. (2012). Violence against Women: A study of Ikire Area, Osun State, Nigeria. African Journal of Social Sciences, 2(2), 131-147.

Parvez, M. A., \& Robina, R. (2010). Mass Media and Women: A Study on Portrayal of Status and Violence. Pakistan Journal of Social Sciences, 3(1), 133-140.

Ramirez, J. M. (2011). Aggression and Crime- An Introduction to a Hot-Topic. The Open Criminology Journal, 4, 48. http://dx.doi.org/10.2174/1874917801104010048

Schutt, R. K. (2004). Investigating the Social world- The Process and Practice of Research (4th ed.). USA: Pine Forge Press.

Smith, C. A., \& Ireland, T. O. (2009). Family Violence and Delinquency. In Krohn et al (Eds.), Handbook on Crime and Deviance- Handbook of Sociology and Social Research. USA: Springer Publisher.

Smith, E. (2008). African-American Men and Intimate Partner Violence. Journal of African American Studies, 12, 156-179. http://dx.doi.org/10.1007/s12111-008-9039-4

Swartz, N. E., Mercier, D. J., \& Curran, M. A. (2012). Influence of Childhood Abuse on Parenting Perspectives of Pregnant Cohabitors. Journal of Family Violence, 27. http://dx.doi.org/10.1007/s10896-012-9452-2

Tailor, K., \& Nicole, L. (2012). Infants Exposed to Intimate and Sex. Journal of Family Violence, 27, 477-488. http://dx.doi.org/10.1007/s10896-012-9441-5

Tortakovsky, E., \& Mezhibovsky, S. (2012). Female Immigrants Victims of Domestic Violence: A Comparison between Immigrants from the Former Soviet Union in Israel and Israel Born Women. Journal of Family Violence, 27. http://dx.doi.org/10.1007/s10896-012-9447-z

Valentine, C., Oehme, K., \& Martin, A. (2012). Correctional Officers and Domestic Violence: Experiences and Attitudes. Journal of Family Violence, 27, 531-545. http://dx.doi.org/10.1007/s10896-012-9448-y

Whitting, J. B., Simmons, L. A., Havens, J. R., Smith, D. B., \& Oka, M. (2009). Intergenerational Transmission of Violence- the Influence of Self - Appraisals, Mental Disorders and Substance Abuse. Journal of Family Violence, 24, 639-648. http://dx.doi.org/10.1007/s10896-009-9262-3 